\title{
Thermal Conductive Networks Constructed by Sialon Fibers in-Situ Synthesized in Barium Aluminosilicate Glass-Ceramic
}

\section{Shaojie Sun}

Harbin Institute of Technology Weihai Campus: Harbin Institute of Technology Weihai

\section{Xinyu Wang}

Harbin Institute of Technology Weihai Campus: Harbin Institute of Technology Weihai

Junjie Zhou

Harbin Institute of Technology Weihai Campus: Harbin Institute of Technology Weihai

Siqi Zhang

Harbin Institute of Technology Weihai Campus: Harbin Institute of Technology Weihai

\section{Kongyu Ge}

Harbin Institute of Technology Weihai Campus: Harbin Institute of Technology Weihai

\section{Hua Yang}

Lanzhou University of Technology

\section{Tao Zhang}

Harbin Institute of Technology Weihai Campus: Harbin Institute of Technology Weihai

\section{Li Xiong}

Harbin Institute of Technology Weihai Campus: Harbin Institute of Technology Weihai

\section{Chunlin Qin}

Harbin Institute of Technology Weihai Campus: Harbin Institute of Technology Weihai

\section{Guangwu Wen}

Shandong University of Technology

Long Xia ( $\nabla$ xialonghit@gmail.com )

Harbin Institute of Technology - Weihai https://orcid.org/0000-0001-7711-2201

\section{Research Article}

Keywords: Ceramic matrix composites, In-situ synthesis, Pressureless sintering, Thermal conductivity

Posted Date: June 16th, 2021

DOI: https://doi.org/10.21203/rs.3.rs-612370/v1 
License: (c) (i) This work is licensed under a Creative Commons Attribution 4.0 International License. Read Full License 


\title{
Thermal conductive networks constructed by Sialon fibers in-situ synthesized in barium aluminosilicate glass-ceramic
}

Shaojie Sun ${ }^{1}$, Xinyu Wang ${ }^{1,}{ }^{*}$, Junjie Zhou ${ }^{1}$, Siqi Zhang ${ }^{1}$, Kongyu $e^{1}$, Hua Yang $^{2}$, Tao Zhang $^{1}$, Li Xiong ${ }^{1}$, Chunlin Qin ${ }^{1}$, Guangwu Wen ${ }^{3}$, Long Xia ${ }^{1, *}$

${ }^{1}$ School of Materials Science and Engineering, Harbin Institute of Technology at Weihai, Weihai 264209, China

${ }^{2}$ School of Science, Lanzhou University of Technology, Lanzhou, 730050, China

${ }^{3}$ School of Materials Science and Engineering, Shandong University of Technology, Zibo 255000, China

${ }^{*}$ Corresponding author, Email: xialonghit@gmail.com

\begin{abstract}
The application of ceramic materials is limited due to the complicated preparation process and intrinsic brittleness. In this work, a pressureless manufacturing route that enables the formation of barium aluminosilicate (BAS) glass-ceramic consisting of internal $\beta$-Sialon fibers with enhanced thermal conductivity is developed. By adjusting the carbon source content, composites with different Sialon contents can be easily fabricated. The thermal conductivity of the sample with $3.5 \mathrm{wt} . \%$ is improved to $5.845 \mathrm{~W} / \mathrm{m} \cdot \mathrm{K}$ with the Sialon content of $26 \mathrm{wt} . \%$ in the composite, which is $112.64 \%$ higher than that of the pure BAS matrix. The theoretical models suggest that the enhanced thermal conductivity is mainly ascribed to the thermal conduction network constructed by Sialon fibers. This work provides a method with industrial application
\end{abstract}


prosperity to fabricate the high temperature ceramic matrix composite of different sizes and complex shapes.

Keywords: Ceramic matrix composites; In-situ synthesis; Pressureless sintering; Thermal conductivity

\section{Introduction}

As the aeronautics and space industries develop dramatically fast, a surging number of rigorous demands are imposed on the thermal stability of structural materials [1-4]. A major requirement of these areas is to develop high temperature materials that combine enhanced strength with high thermal conductivity and low coefficient of thermal expansion [5-7]. In these cases, glass-ceramic material has attracted great attention as a promising material for high temperature structural matrix $[8,9]$. Compared with other ceramic materials, glass-ceramic material has the advantages of better thermal stability, lower coefficient of thermal expansion [10-12]. Barium aluminosilicate $\left(\mathrm{BaAl}_{2} \mathrm{Si}_{2} \mathrm{O}_{8}\right.$, BAS) is an advanced glass-ceramic material known for the excellent high temperature stability. It possesses high melting point $\left(\sim 1760{ }^{\circ} \mathrm{C}\right)$ [13], and the monolithic BAS (celsian) exhibits good thermal shock resistance due to its low coefficient of thermal expansion of $2.29 \times 10^{-6}{ }^{\circ} \mathrm{C}^{-1}$ from RT (room temperature) to $1000^{\circ} \mathrm{C}$ [14]. Significantly, its most distinct characteristic is that a large number of instant $\mathrm{Ba}-\mathrm{Al}-\mathrm{Si}-\mathrm{O}$ liquid phases appeared during the sintering process promoting the densification of the composites [15]. Therefore, BAS glass-ceramic is not only a structural matrix, but also acts as a liquid phase sintering additive [16]. However, the intrinsic brittleness of the BAS has become the neck problem for its broad application, and several manufacturing 
routes have been proposed to enhance its toughness [17-24]. Methods that allow for the incorporation of nano-scale second phase of high thermal ability have been found to be effective in simultaneously enhancing the strength and thermal stability of the composites [25-27]. In these approaches, the second phases, such as $\mathrm{BN}$ [25], $\mathrm{Si}_{3} \mathrm{~N}_{4}$ [26], were added by being mixed with ceramic precursor powders and formed by hot compression molding method. Although the mechanical properties have been improved, the bonding between the second phase and matrix presents unsatisfactory due to the external introduction. Moreover, industrial challenges have been posted for commercializing this technique, since the size and shape of materials prepared by hot pressing have certain limitations [28-30].

Sialon is one kind of structural ceramic widely used in high temperature engineering systems, except for the superior wear and thermal shock resistance [31-35], the advantages of low-cost preparation and easy manufacture make it often used in in-situ synthesis process [36-38]. Carbothermal reduction nitridation [39-42] has been proved to be a common method to synthesize the Sialon phase in the Al-Si-O-N-C system. However, the disadvantages are equally notable that the degree of nitridation is limited by the hot pressing and preforming process, resulting in relatively low production and surplus of raw material. Thereby, the novel combination of the BAS and Sialon has both advantages of them, BAS could promote the formation of Sialon phase through pressureless process, meanwhile, the in-situ synthesized Sialon phase would strengthen and toughen the BAS matrix.

On the other hand, few reports have been found with respect to the influences of second 
nano-scale phase distribution on the thermal conductivities of ceramic matrix composites. The construction process of the thermal conduction network built by the second phase requires an appropriate approach supported by a theoretical framework. Herein, we report a one-step approach to fabricate the BAS matrix and the internal Sialon phase simultaneously by direct powder sintering without pressure. Sialon phase appears as one-dimensional structure, and the content and distribution of which are related to the carbon content. It has a significant enhancement effect on the thermal conductivity and thermal shock resistance of the composite. Further, the influences of structure on the thermal conductivities are investigated systematically. This work potentially provides a new preparation method for the ceramic matrix composites in complex shapes, which could meet the requirements of the aerospace industry enhancement. Meanwhile, a new perspective is introduced to explore the relationship between the microstructure and the thermal conductivity of the ceramic matrix composite.

\section{Experimental}

\subsection{Materials}

$\mathrm{Al}\left(\mathrm{NO}_{3}\right)_{3} \cdot 9 \mathrm{H}_{2} \mathrm{O}, \mathrm{Ba}\left(\mathrm{CH}_{3} \mathrm{COO}\right)_{2}, \mathrm{LiNO}_{3}$ and $\mathrm{Fe}\left(\mathrm{NO}_{3}\right)_{3} \cdot 9 \mathrm{H}_{2} \mathrm{O}$ were purchased from Shanghai Sinopharm Chemical Reagent Co., Ltd. (AR 99.9 \%). $\mathrm{SiO}_{2}$ sol (solid content 30 wt.\%) was purchased from Qingdao Yuminyuan Silica Reagent Factory. And ammonia and acetylene black were purchased from Technological Development Zone Fine Chemical Plant and Dongguan Kelude Chemical Company, respectively. 


\subsection{Preparation process}

The fabrication steps are illustrated in Figure 1. In this work, the sol-gel method was adopted to prepare the barium aluminosilicate with iron ion precursors powder, and detailed process are available in our previous work [22]. Additionally, $\mathrm{LiNO}_{3}$ was added to accelerate the formation of hexacelsian in BAS matrix [43]. The carbothermal reduction nitridation was employed to in-situ synthesize $\beta$-Sialon fibers. The proper amount of acetylene black, as the carbon source, and precursors powders were mixed thoroughly with alcohol by ball milling process at $700 \mathrm{r} / \mathrm{min}$ for $8 \mathrm{~h}$, followed by drying for 12 hours. The dried mixture was then ball milled to powders with particles size under 200 mesh. The precursor powders were put in the crucible directly, then placed in the tube furnace sintered at $1400^{\circ} \mathrm{C}$ for $3 \mathrm{~h}$ in nitrogen. Finally, the dense bulk samples were prepared, which were denoted as C2.5, C3, C3.5 and C4, corresponding to 2.5 wt. $\%, 3.0$ wt.\%, 3.5 wt.\% and 4.0 wt.\% carbon content, respectively. The chemical composition of the samples is listed in Table 1. It is noteworthy that samples could imitate the shape of the crucible (Figure. S1, Supporting Information, ESI).

TABLE 1 Chemical composition of composites with different carbon content(wt\%)

\begin{tabular}{ccccccc}
\hline Sample & Carbon & $\mathrm{Al}\left(\mathrm{NO}_{3}\right)_{3} \cdot 9 \mathrm{H}_{2} \mathrm{O}$ & $\mathrm{Ba}\left(\mathrm{CH}_{3} \mathrm{COO}\right)_{2}$ & $\mathrm{LiNO}_{3}$ & $\mathrm{SiO}_{2}$ sol & $\mathrm{Fe}\left(\mathrm{NO}_{3}\right)_{3} \cdot 9 \mathrm{H}_{2} \mathrm{O}$ \\
\hline $\mathrm{C} 2.5$ & 2.5 & 52.94 & 14.43 & 1.95 & 28.18 & 4.88 \\
$\mathrm{C} 3$ & 3.0 & 52.67 & 14.36 & 1.94 & 28.03 & 4.85 \\
$\mathrm{C} 3.5$ & 3.5 & 52.40 & 14.28 & 1.93 & 27.89 & 4.83 \\
$\mathrm{C} 4.0$ & 4.0 & 52.13 & 14.21 & 1.92 & 27.74 & 4.80 \\
\hline
\end{tabular}

\subsection{Material characterization}

A field emission scanning electron microscope (MERLIN Compact, ZEISS) was used to carry out morphological characterization on the fracture surfaces of samples sputter- 
coated with gold. The X-ray diffractometer (XRD, DX-2700) equipped with Ni-filtered $\mathrm{Cu} \mathrm{K} \alpha$ radiation was carried out to identify the phases in the sample. High resolution transmission electron microscopy (HRTEM) analysis was performed on the JEM2100 microscopy to determine the micromorphology of samples, the crystal plane spacing of the samples was measured by HRTEM, and compared with PDF card. The TEM samples were prepared by traditional mechanical grinding method followed by the final Argon ion-beam thinning.

The thermal conductivity is calculated according to the following Eq. (1):

$$
K=\rho \times \alpha \times C_{p}
$$

Where $\rho, \alpha$, and $C_{p}$ are the density, thermal diffusivity, and specific heat capacity of the samples, respectively. Density was calculated by the Archimedes method. Specific heat capacity and thermal diffusion coefficient were measured by using the DSC instrument and the flash method using a thermal diffusivity analyzer, respectively.

The coefficient of thermal expansion was measured by using a thermal expansion analyzer (DIL 402c, Netzsch) on the rectangular-shaped samples with size of $\Phi 5.5-6$ $\mathrm{mm} \times 5 \sim 15 \mathrm{~mm}$. The thermal shock resistance of composites can be estimated by the residual strength after quenching. The thermal analysis was conducted with a thermogravimetric-differential scanning calorimetry (TG-DSC, Mettler Toledo) from 50 to $1500{ }^{\circ} \mathrm{C}$ with a heating rate of $10^{\circ} \mathrm{C} / \mathrm{min}$.

The flexural strength of composites was measured using three-point bending method conducted on the Instron 5967 universal test machine with a span of $30 \mathrm{~mm}$ at loading rate of $0.5 \mathrm{~mm} / \mathrm{min}$. The ceramic composites were ground into $4 \mathrm{~mm}$ thick using surface 
grinding machine equipped 600 mesh grinding wheel. After this, 5 testing specimens with a size of $3 \times 4 \times 40 \mathrm{~mm}$ were cut out by inside diameter slicer. The flexural strength was calculated by following Eq. (2):

$$
\sigma_{f}=\frac{3 P L}{2 b W^{2}}
$$

Where $\sigma_{f}$ is the flexural strength, $P$ is the maximum load $(\mathrm{N}), L$ is the span $(\mathrm{mm}), b$ and $W$ are the width and height of sample $(\mathrm{mm})$.

\section{Results and Discussion}

\subsection{The process of sintering}

In this work, the sintering process involves relatively complex crystallization and phase transformation process, which can be divided into two parts, the formation of BAS matrix and Sialon fibers. In order to track the detailed material transmutation, the DSCTG scan was carried out in a temperature range of RT- $1500{ }^{\circ} \mathrm{C}$ with a heating rate of $10{ }^{\circ} \mathrm{C} / \mathrm{min}$ in a nitrogen atmosphere. Figure 2 presents the DSC-TG scans of the C3.5 sample. A conspicuous endothermal peak appears in the plot at about $630{ }^{\circ} \mathrm{C}$, which is attributed to the melting of the $\mathrm{BaO}-\mathrm{Al}_{2} \mathrm{O}_{3}-\mathrm{SiO}_{2}$ glass, based on the previous research on BAS matrix [44-45]. A large amount of Ba-Al-Si-O liquid phases appears when the temperature reaches the eutectic temperature of the BAS glass, promoting the densification of the sample. This is also the principle that the precursor powders can be directly used for sintering. As the temperature continues to rise above $1000{ }^{\circ} \mathrm{C}$, the curve maintains smooth upward trend, some exothermal peaks could be seen in the marked yellow area, which indicates the crystallization of the $\mathrm{BAS}$, the $\mathrm{BaAl}_{2} \mathrm{Si}_{2} \mathrm{O}_{8}$ 
crystal forms from the liquid phase [46]. Then Sialon fibers start to grow on the BAS matrix by the V-L-S growth mechanism (the detailed growth process of Sialon s was discussed in our previous work [47]), which are reflected in the exothermal peak at $1370{ }^{\circ} \mathrm{C}$. Due to the crystallization of the BAS and the growth of the Sialon, the mass of the sample is increased in the corresponding temperature range, as red curve shown in Figure 2. It is noteworthy that the rise of the curve becomes suddenly steeper as marked in figure 2, which represents that the phase transformation process becomes different. It can be explained that the crystallization and the growth of the Sialon take place simultaneously as temperature continues to rise. During the cooling process, the Ba-Al-Si-O liquid phases transform into the amorphous Ba-Al-Si-O glass phases, combined with the $\mathrm{BaAl}_{2} \mathrm{Si}_{2} \mathrm{O}_{8}$ crystallized before, the $\mathrm{BAS}$ glass-ceramic matrix is formed. The theoretical schematic of the sintering process is shown at the bottom of Figure 1.

\subsection{Structure and morphology}

Figure 3 shows the SEM images of the samples with different carbon contents. As demonstrated in the four samples, the string-like structures with large aspect ratio could be seen. Moreover, it can be observed obviously that the quantity and the distribution of the fibers are moderated with the carbon content, which plays a role of providing the growing points. For sample $\mathrm{C} 2.5$, the fiber-like structures are distributed evenly in matrix, however, the content of the fibers is so low that they could not connect with each other. From 3.0 wt.\% to 3.5 wt.\%, the quantity of the fibers increases and they tend to gather together into the cotton-like network structure (Figure 3(e) and (f)), the 
high contact area of matrix particles facilitates the approaching of fibers, resulting in the partially formation of the thermal conductivity path. And the diameters of the fibers are about $50-300 \mathrm{~nm}$. As the carbon content reaches $4.0 \mathrm{wt} . \%$, the diameters of the fiber increases to about $500 \mathrm{~nm}$, and the quantity of the fibers reduces significantly, which is attributed to the liquid phase appearing in the sintering process promotes the accumulation of the fibers (Figure 3(h)), then fibers with larger diameter forms. Additionally, the density of the samples is presented in Figure S2 (ESI), due to the same preparation method, the density of the material is similar in the range of $2.62-2.89 \mathrm{~g} / \mathrm{cm}^{3}$. And the density of the samples increases with the increasing Sialon fiber content, which can be attributed to the existence of Sialon fibers enhances the binding force between particles and fills the gap between particles. Thus, the influence of density and porosity on heat conduction can be excluded, the structure and contribution factors of the Sialon fibers should be emphasized.

Compared with our previous study [47], the content of the material is adjusted in this work, $\mathrm{Li}^{+}$is added to promote the phase transformation of monoclinic-celsian matrix, which has better compatibility with Sialon phase [48]. The XRD patterns of composites with different carbon contents are shown in Figure 4. The monoclinic-celsian phase $\left(\mathrm{BaAl}_{2} \mathrm{Si}_{2} \mathrm{O}_{8}\right)$ is the main phase in all samples, the diffraction peaks of $\beta$-Sialon $\left(\mathrm{Si}_{2} \mathrm{Al}_{4} \mathrm{O}_{4} \mathrm{~N}_{4}\right)$ were detected at $2 \theta=13.21^{\circ}, 22.99^{\circ}, 26.70^{\circ}, 32.51^{\circ}$, and $50.9^{\circ}$, which correspond to (100), (110), (101), (301) diffraction planes of $\beta$-Sialon, respectively. The content of Sialon phase was calculated, and results and the related parameters are 
presented in Table 2 and Table S1 (ESI), respectively. The Sialon content in sample C3.5 reaches the maximum corresponding to the microstructure shown in Figure 3.

Figure 5 shows the TEM images of the C3.5 sample. Typical TEM images of the rodlike structure of $\beta$-Sialon are shown in Figure 5(a) and (b). The high aspect ratio fiberlike Sialon structure is combined well with the matrix. The spacing between adjacent lattice planes is $0.343 \mathrm{~nm}$, which corresponds to (100) of $\beta$-Sialon $\left(\mathrm{Si}_{2} \mathrm{Al}_{4} \mathrm{O}_{4} \mathrm{~N}_{4}\right)$. As shown in Figure 5(e), the $\mathrm{Si}, \mathrm{Al}, \mathrm{O}, \mathrm{N}$ elements are distributed evenly in rod-like structure, which is consistent with the constituent elements of Sialon phase.

TABLE 2 Semi-quantitative amount of Sialon in sample with different carbon contents

\begin{tabular}{ccccc}
\hline $\begin{array}{l}\text { Carbon } \\
\text { content }\end{array}$ & $2.5 \mathrm{wt} \%$ & $3.0 \mathrm{wt} \%$ & $3.5 \mathrm{wt} \%$ & $4.0 \mathrm{wt} \%$ \\
\hline $\begin{array}{l}\beta-\text { Sialon } \\
\text { Content }\end{array}$ & 8 & 11 & 26 & 17 \\
\hline
\end{tabular}

\subsection{Thermal conductivity behaviours of Sialon/BAS composites}

The influences of Sialon fiber content on the thermal conductivity of the BAS glassceramic matrix composite are shown as green line in Figure 6. Actually, a pronounced enhancement of effective thermal conductivity is achieved by the growth of the Sialon content in composites. Compared with the pure BAS glass-ceramic matrix synthesized by the same method, the thermal conductivity of the composites could be enhanced by $22.2 \%-133.8 \%$. As to the samples with lower Sialon content, Sialon fibers are dispersed in the matrix with small contact area between each other. Hence, the insufficient content of fibers and limited contact points result in a limitation to the efficient phonon transfer path. For samples with high Sialon fiber content (Sample 
C3.5), as shown in Figure 3, Sialon fibers construct the network with largely increased contact areas, moreover, the fibers dispersed in the BAS matrix could enhance the thermal conductivity of composite and improve the network-density. The large contact area permits ease of heat flows and promoted phonon diffusion in the composites to form a highly effective heat conduction network. Therefore, the thermal conductivity of C3.5 sample has been significantly improved, whose value reaches $5.845 \mathrm{~W} / \mathrm{m} \cdot \mathrm{K}$.

\subsection{Theoretical modeling of thermal conductivity in composites}

To further explore the influence of fiber content and distribution morphology on thermal conductivity of the composites from a theoretical point of view. Two classical heat conduction models, parallel conduction model and series conduction model are employed to describe the thermal conductivity of the samples [49-50]. In the parallel conduction model, thermal conductivity of the composite would reach the highest theoretical value under the assumption that all fillers tend to gather to a conductive block and another block of ceramic is arranged in parallel in the direction of thermal flux, which is also assumed that particles fully contact with each other to form an ideal heat conduction network. And for the series conduction, thermal conductivity is the lowest in the case where filler area and matrix area are arranged in a series in the direction of thermal flux [51], the detailed information was provided in ESI. Above all, the extreme values of the thermal conductivities could be estimated according to the distribution of fillers in the composite. Thereby the distribution morphology of the Sialon phase, which acts as filler, could be predicted by comparing the experimental value with the calculated value. 
Figure 6 shows the experimental data of the composites compared with the calculated values by parallel model and series model. It presents that the experimental results are closer to the series conduction model value at lower Sialon content. With the increase of the Sialon content, the experimental data curve appears an upward trend approaching the parallel model calculated curve. Generally, it is demonstrated that the heat transfer model of the composites changes from the part series conduction model to part parallel model with the increase of the Sialon content. One of the mechanisms accounting for the transform is the increase of the Sialon filler with higher thermal conductivity. Nevertheless, the content factor alone cannot explain the significant enhancement in the thermal conductivity. The main reason could be attributed to the thermal conductivity networks formed by the fibers dispersed on the BAS matrix.

In order to get insight to the heat conduction mechanism in the composites, two theoretical models, Hashin-Shtrikman (HS) model [52] and Y. Agari's semi-empirical model [53] are employed to further improve the accuracy of the theoretical value in the practical situation. In these two models, the BAS is considered as a whole matrix while the Sialon is considered as the filler with high thermal conductivity.

The Hashin-Shtrikman model including two boundary values pays attention to the arrangement behavior between filler phase and matrix. The Hashin-Shtrikman lower boundary $\left(\mathrm{K}^{\mathrm{HS}-}\right)$ is obtained with an assumption of a high conducting phase (Sialon) surrounded by a lower conducting phase (BAS matrix), and the upper boundary $\left(\mathrm{K}^{\mathrm{HS}+}\right)$ is in the case that the BAS is surrounded by Sialon phase, which can be calculated by following Eq. (3) and (4), respectively: 


$$
\begin{aligned}
& K^{H S-}=\frac{2 K_{m}+K_{f}-2 V_{f}\left(K_{m}-K_{f}\right)}{2 K_{m}+K_{f}+W_{f}\left(K_{m}-K_{f}\right)} K_{m} \\
& K^{H S+}=\frac{2 K_{f}+K_{m}-2 V_{m}\left(K_{f}-K_{m}\right)}{2 K_{f}+K_{m}+V_{f}\left(K_{f}-K_{m}\right)} K_{f}
\end{aligned}
$$

Where $K_{m}$ is the thermal conductivity of the BAS matrix, $K_{f}$ is the thermal conductivity of the Sialon fibers, $V_{f}$ is the volume fractions of Sialon phases in the composite, $V_{m}$ is the volume fractions of BAS matrix in the composite.

The Hashin-Shtrikman upper and lower boundaries are presented in Figure 7(a). The experimental values present a rising tendency from the lower boundary to the upper boundary, which indicates that the model of high effective thermal conductive Sialon network surrounding the particles of BAS matrix is more suitable to describe actual heat conduction process in the composite with the increasing Sialon content.

Moreover, based on the Hashin-Shtrikman model, determined factor $X_{\text {interconnectivity }}$ is introduced to quantitatively estimate interconnectivity of the conducting phase; the $\eta$ represents the thermal conductivity improvement of the composite per $1 \mathrm{wt} \%$ loading increase (The details see the ESI).

As illustrated in Figure7 (b) and (c), the $X_{\text {interconnectivity }}$ and $\eta$ are raised with the increasing content of Sialon content, which are increased by $118.7 \%$ and $285.2 \%$ at Sialon content of $26 \mathrm{wt} . \%$, the overlapped area and junction of the filler phase increases with the dispersed state of Sialon phase in C3.5. With the increase of thermal conductive filler, the thermal conductivity also presents an increasing trend. In view of the results, the parameters $X_{\text {interconnectivity }}$ and $\eta$ provide a new perspective for the efficiency evaluation of the heat transport for Sialon/BAS composite. 
The Y. Agari's semi-empirical model focuses on the disperse state of the filler and the intrinsic characteristic of the matrix, which is introduced as following Eq. (5),

$$
\log K_{C}=V_{f} C_{2} \log K_{f}+\left(1-V_{f}\right) \log \left(C_{1} K_{m}\right)
$$

Where $C 1$ and $C 2$ are obtained via fitting the experimental data, $C 1$ represents a factor relating to the intrinsic crystal characteristic of the matrix, and $C 2$ indicates a factor presenting the theoretical possibility of the formation of the conductive network of the filler phase. The closer the value of $C 2$ is to 1 , indicating that it is easier to form a heat conduction path. As shown in Figure 7(d), Agari model appears to fit the experimental data, the parameters $C 1$ and $C 2$ are given in Table S2 (ESI). As shown in Table S2, square values of fitting correlation coefficient $\left(R^{2}\right)$ is 0.972 , suggesting that the Agari model can effectively describe the thermal conductivity behaviors with high precision. Most notably, the fitting value $C 2$ value of the composite is 1.04 , indicating that Sialon fiber tends to form a heat conduction path in the composites.

To sum up, the formation of the heat conduction network arranged by the highly dispersed Sialon phases could be confirmed the microstructure and theoretical model analysis. However, the thermal resistance caused by the overlapped areas between the Sialon fibers should be taken into consideration, which can be classified into interfacial thermal resistance and contact thermal resistance. The interfacial thermal resistance is formed due to the difference of phonon spectra between filler and matrix, which is related to the arrangement and density of atoms [54], the interfacial thermal resistance in the composite could be calculated as follows [55]: 


$$
\frac{K_{c}}{K_{m}}=\frac{2 / 3\left[V_{f}-V_{f c}(p)\right]^{t(p)}}{H(p)+1 /\left(\frac{K_{x}}{K_{m}}-1\right)}+1
$$

where $\mathrm{Km}$ represents the thermal conductivity of the matrix, $p$ represents the aspect ratio ( $p=L / d, L$ and $d$ are the length and diameter of the Sialon, respectively), $K x$ indicates the effective thermal conductivity of the Sialon phases, $V f_{c}(p)$ is the critical volume fraction for the nonlinear conductivity variation $\left(V f_{c}(p) \sim 1 / p\right)$, and $t(p)$ is a critical conductivity exponent for a given aspect $\operatorname{ratio}(p) . H(p)$ is well-known geometrical factors which could be calculated using the aspect ratio $p$ (See details equation in ESI).

The theoretical fitting curve calculated by Eq. (6) and experimental data for samples with different Sialon contents are shown in Figure 7(e). It can be seen clearly that the interfacial thermal resistance model could provide the best fit for the experimental data with the $R^{2}$ higher than 0.976 , and well described the nonlinear thermal conductivity behavior in the sample. The resistance exists in the overlapped areas of the fibers, however, it barely affects the heat transfer in the composite due to the strong bonding interface between the in-situ grown fiber and the matrix. The relative parameters are presented in Table S2 (ESI).

On the other hand, the Sialon phases are overlapped with each other above the percolation threshold, which would create a barrier to the heat conduction and results in the ineffective heat flow. The contact thermal resistance could be described by following Eq. (7) [56]: 


$$
K_{c}-K_{m}=K_{0}{\frac{W_{f}-V_{f c(p)}}{1-V_{f c(p)}}}^{t(p)}
$$

where $K_{0}$ is a parameter that takes into account the conductivity of Sialon phases and their contacts with each other, which can represent the effective conductivity of the filler concerned with the practical construction; $t(p)$ is a critical conductivity exponent for a given aspect $\operatorname{ratio}(p)$. The experimental value and the fitting curve are shown in Figure 7(f), the curve is in good agreement with the experimental data, and the fitting correlation coefficient value given in Table S2 (ESI) is 0.968, which proves that the model could describe the heat conduction behavior in the composite and the contact thermal resistance exists between the Sialon fibers. The fitted $K_{0}$ value is 15.45 , which presents the effective thermal conductivity of the Sialon heat conduction path. The calculated value is close to the theoretical conductivities of Sialon phase (16.48), which means that the contact thermal resistance in the Sialon-Sialon contact is relatively low. Due to the highly dispersed and closely accumulation of the fibers, the extensive contact and continuity of network structure would reduce the interfacial and contact thermal resistance caused by transitional contact, and it will not hinder the heat transfer in the contact area.

The Schematic of the composites with different Sialon contents combined with heat conduction path are presented in Figure 8. As shown in Figure 8(a), with Sialon fibers increasing in the matrix, the overlapped areas between Sialon fibers build more heat conduction pathways, which are beneficial to phonon transmission. However, the contact thermal resistance at line-line interconnections is limited due to the highly dispersed fibers and the continuous network. Owing to the reduction of the Sialon-BAS 
matrix interface, the contact thermal resistance plays a dominant role in the thermal conduction. As shown in Figure 8(b), for the sample with lower Sialon content, the dispersed distribution of the Sialon fibers grown in the BAS matrix made it difficult to overlap with each other. Therefore, the thermal network would hardly be constructed between the Sialon phase, phonon transmission between fillers would be affected. Above all, the difference of thermal conductivity between samples with different Sialon contents could be explained.

\subsection{Numerical simulation of thermal conductivity}

The temperature field of the samples with different Sialon contents is simulated by the finite element method. Based on the script of random distribution of fibers, a threedimensional geometric model of the composite is obtained. The length and diameter of the Sialon fiber are assigned as the average value of $1000 \mathrm{~nm}$ and $200 \mathrm{~nm}$, respectively. And the volume fraction is set according to the actual measured value. Then the model is imported into finite element method software. The Steady-state thermal module in workbench plant form is employed to simulate the heat conduction process. The related engineering data used in the simulation could be found in Table S3 (ESI). According to the actual situation, the heat convection between samples and air at the top boundary is considered to simulate heating process at room temperature. The initial temperature is set at the bottom face as $500{ }^{\circ} \mathrm{C}$, and at the top face as $22{ }^{\circ} \mathrm{C}$ presenting the heat source and flowing air, respectively. The final state temperature distributions of all formulas are shown in Figure 9. As shown in the Figures 9(a)-(d), from the bottom to top, the distribution of the temperature in samples with different Sialon contents present 
different gradients. The sample with more Sialon contents (C3.5) in Figure 9(c), the temperature distribution is relatively uniform, the maximum temperature at the top is $493^{\circ} \mathrm{C}$. While the temperature in the sample with lower Sialon content $(\mathrm{C} 2.5)$ in Figure 9(a) has a large gap, the maximum temperature is $485^{\circ} \mathrm{C}$. Based on the principle that the heat could be transferred efficiently in a material with higher thermal conductivity, the simulation provides a relatively intuitive result to prove that the samples with high Sialon contents have higher thermal conductivity.

\section{Conclusions}

In summary, bulk BAS matrix composites with different contents of in-situ synthesized Sialon fiber was fabricated by pressureless powder sintering method, and the samples could imitate the shape of the crucible. The morphology and distribution of the Sialon fibers could be tailored by the carbon content, and the experimental results reveal that the thermal conductivity of composites is increased with the Sialon content increasing. By incorporating the structure and distribution factors of Sialon phase, the dependence of the thermal conductivity on Sialon content is well fitted by analytical models. The considerable overlap areas of the Sialon phase which promote the construction of highly effective heat conduction network is the main reason for the enhancement of the thermal conductivity. Consequently, the pressureless sintered Sialon/BAS composites create a critical contribution to meet the application requirements of high temperature materials in different sizes and complex shapes.

\section{Declaration of Competing Interest}

The authors declare no competing financial interest. 


\section{Acknowledgements}

This work was supported by the National Natural Science Foundation of China (Grant

No 51972078), Key Laboratory of Advanced Structural-Functional Integration

Materials \& Green Manufacturing Technology, Harbin Institute of Technology, Harbin, 150001, China.

\section{References:}

[1] Chen D, Zhao J, Jiang X. Synthesis and characterization of silver substituted strontium phosphate silicate apatite using solid-state reaction for osteoregenerative applications. Bioengineered 2021, 12: $1111-25$.

[2] Iqbal T, Mostafa M, Ishtiaque MS, Rahman MJ, Choudhury S. Effect of Ce-Mn Codoping on the Structural, Morphological and Electrical Properties of the $\mathrm{BaTiO}_{3}$ Based Ceramics. Biointerface Res Appl Chem 2021, 11: 12215-26.

[3] Pirzada TJ, Liu D, Ell J, Barnard H, Sulak I, Galano M, Marrow TJ, Ritchie RO. In situ observation of the deformation and fracture of an alumina-alumina ceramic-matrix composite at elevated temperature using X-ray computed tomography. J Eur Ceram Soc 202, 41: 4217-30.

[4] Hsiang HI, Chen CC, Yang SY. Microwave dielectric properties of $\mathrm{Ca}_{0.7} \mathrm{Nd}_{0.2} \mathrm{TiO}_{3}$ ceramic-filled $\mathrm{CaO}-\mathrm{B}_{2} \mathrm{O}_{3}-\mathrm{SiO}_{2}$ glass for LTCC applications. J Adv Ceram 2019, 8: 345-51.

[5] Gudarzifar H, Rezvani A, Sabbaghi S. Morphological investigation of Graphene Oxide/Polyacrylamide super-elastic nanocomposite by a solution polymerization process with enhanced rheological property and thermal conductivity. Int J Nano Dimens 2021, 12: 20-36.

[6] Kultayeva S, Kim Y-W, Song I-H. Effects of dopants on electrical, thermal, and mechanical properties of porous SiC ceramics. J Eur Ceram Soc 2021, 41: 4006-15

[7] Zhu B, Chen C, Yao Z, Chen J, Jia C, Wang Z, Tian R, Tao L, Xue F, Hng H. Multiple doped ZnO with enhanced thermoelectric properties. J Eur Ceram Soc 2021, 41: 4182-8.

[8] Yao C, Ahmed MH, De Grave L, Yoshihara K, Mercelis B, Okazaki Y, Van Landuyt KL, Huang C, Van Meerbeek B. Optimizing glass-ceramic bonding incorporating new silane technology in an experimental universal adhesive formulation. Dental materials: official publication of the Academy of Dental Materials 2021, 37: 894-904.

[9] Simba BG, Ribeiro MV, Alves MFRP, Amarante JEV, Strecker K, dos Santos C. Effect of the temperature on the mechanical properties and translucency of lithium silicate dental glass-ceramic. Ceram Int 2021, 47: 9933-40.

[10]Feng Y, Xia L, Ding C, Yang H, Xu G, Zhang T, Xiong L, Qin C, Wen G. Boosted multi- 
polarization from silicate-glass@ $@$ GO doped with modifier cations for superior microwave absorption. J Colloid Interface Sci 2021, 593: 96-104.

[11]Zandona A, Arias AM, Gutbrod M, Helsch G, Weber AP, Deubener J. Spray-Dried TiO 2 (B)Containing Photocatalytic Glass-Ceramic Nanobeads. Adv Funct Mater 2021, 31: 7.

[12] Xiong SZ, Liu YY, Jankowski P, Liu Q, Nitze F, Xie K, Song JX, Matic A. Design of a Multifunctional Interlayer for NASCION-Based Solid-State Li Metal Batteries. Adv Funct Mater 2020, 30: 10 .

[13] Yoshiki B, Matsumoto K. High-Temperature Modificat on of Barium Feldspar. J Am Ceram Soc 2006, 34: 283-6.

[14] Bansal NP. Celsian formation in fiber-reinforced barium aluminosilicate glass-ceramic matrix composites. Mater Sci Eng A 2003, 342: 23-7.

[15]Lee KT, Aswath PB. Synthesis of hexacelsian barium aluminosilicate by a solid-state process. $J$ Am Ceram Soc 2000, 83: 2907-12.

[16]Feng Y, Liu L, Zhang H, Wen B. Thermal shock behavior of $30 \mathrm{wt} \% \mathrm{BAS} / \mathrm{Si}_{3} \mathrm{~N}_{4}$ self-reinforced composite. J Alloys Compd 2010, 493: 272-5.

[17] Allemand A, Guerin C, Besnard C, Billard R, Le Petitcorps Y. A comparison between a new Ultra Fast Pressureless Sintering (UFPS) technology and Spark Plasma Sintering (SPS) for Barium AluminoSilicate metastable phase. J Eur Ceram Soc 2021, 41: 1524-9.

[18] Meng QY, Zhao ZH, Sun YQ, Lie XL, Ji HM. Low temperature pressureless sintering of dense silicon nitride using $\mathrm{BaO}-\mathrm{Al}_{2} \mathrm{O}_{3}-\mathrm{SiO}_{2}$ glass as sintering aid. Ceram Int 2017, 43: 10123-9.

[19] Casas-Luna M, Ravaszova S, Skalka P, Gejdos P, Jech D, Slamecka K, Kaiser J, Dvorak K, Celko L. Thermal cycling effect on the phase stability and fracture resistance of synthetic barium/magnesium aluminosilicate systems. Ceram Int 2020, 46: 24129-36.

[20] Tong ZW, Ji HM, Li XL, Liu ZD. Microstructure control and optimization of low temperature pressureless sintered silicon nitride-barium aluminosilicate composites. J Eur Ceram Soc 2020, 40: 4177-83.

[21] Besnard C, Allemand A, David P, Maille L. Synthesis of hexacelsian barium aluminosilicate by film boiling chemical vapour process. J Eur Ceram Soc 2020, 40: 3494-7.

[22] Silva MJ, Pontuschka WM, Bartolome JF, Jasinski P, Karczewski J, Reis ST. Ionic conductivity behavior by activated hopping conductivity (AHC) of barium aluminoborosilicate glass-ceramic system designed for SOFC sealing. J Eur Ceram Soc 2019, 39: 3103-11.

[23] Wu SS, Han XZ, Xia L, Xiao B, Hou YZ, Zhang CJ, Shi B, Huang XX, Wen GW. The evolution of carbon fibers with $\mathrm{Fe} 3+$ doping and effects on the mechanical properties of $\mathrm{Cf} / \mathrm{BAS}$ composites. Compos Pt B-Eng 2019, 163: 447-54.

[24] Mao HJ, Chen XY, Wang FL, Zhang WJ. Effects of alkaline earth oxides on the densification and microwave properties of low-temperature fired $\mathrm{BaO}-\mathrm{Al}_{2} \mathrm{O}_{3}-\mathrm{SiO}_{2}$ glass-ceramic/ $\mathrm{Al}_{2} \mathrm{O}_{3}$ composites. 
J Mater Sci 2019, 54: 12371-80.

[25] Tong ZW, Liu ZD, Yu HJ, Zhang BJ, Li XL, Su D, Ji HM. Design, thermal shock resistance of dense $\mathrm{BaO}-\mathrm{Al}_{2} \mathrm{O}_{3}-\mathrm{SiO}_{2}$ glass $/ \mathrm{Si}_{3} \mathrm{~N}_{4}$-barium feldspar coating for porous $\mathrm{Si}_{3} \mathrm{~N}_{4}$ ceramic. $J$ Am Ceram Soc 10.1111/jace.17724: 11 .

[26] Li Q, Cai DL, Yang ZH, Duan XM, Li DX, Sun YS, Wang SJ, Jia DC, Joachim B, Zhou Y. Effects of BN on the microstructural evolution and mechanical properties of BAS-BN composites. Ceram Int 2019, 45: 1627-33.

[27] Liu ZD, Tong ZW, Yue S, Li XL, Ji HM. Novel design of a $\mathrm{Si}_{3} \mathrm{~N}_{4} / \mathrm{BaO}-\mathrm{Al}_{2} \mathrm{O}_{3}-\mathrm{SiO}_{2}$ coating with a heterogeneous- layer structure on porous $\mathrm{Si}_{3} \mathrm{~N}_{4}$ ceramic. Ceram Int 2021, 47: 1456-61.

[28] Borhan AI, Gromada M, Nedelcu GG, Leontie L. Influence of ( $\left.\mathrm{CoO}, \mathrm{CaO}, \mathrm{B}_{2} \mathrm{O}_{3}\right)$ additives on thermal and dielectric properties of $\mathrm{BaO}-\mathrm{A} 12 \mathrm{O} 3-\mathrm{SiO} 2$ glass-ceramic sealant for OTM applications. Ceram Int 2016, 42: 10459-68.

[29] Kong JH, Ma HJ, Jung WK, Hong J, Jun K, Kim DK. Self-reinforced and high-thermal conductivity silicon nitride by tailoring $\alpha$ - $\beta$ phase ratio with pressureless multi-step sintering. Ceram Int 2021, 47: 13057-64.

[30] Byun J, An H, Hong J, Chun DW, Moon J. Thermoelectric performance of n-type polycrystalline SnSe with surface depletion by pressureless sintering. Appl Surf Sci 2021, 544: 5.

[31] Tsabit AM, Yoon D-H. Transparent polycrystalline gamma-AlON fabricated using a hybrid sintering process. Scr Mater 2021, 194:113715.

[32] Kshetri YK, Chaudhary B, Kim TH, Kim HS, Lee SW. Yb/Er/Ho-alpha-SiAlON ceramics for hightemperature optical thermometry. J Eur Ceram Soc 2021, 41: 2400-6.

[33] Wang FH, Dong BB, Ke NW, Yang MY, Qian RC, Wang JW, Yu JL, Hao LY, Yin LJ, Xu X, Agathopoulos S. Superhydrophobic beta-Sialon-mullite ceramic membranes with high performance in water treatment. Ceram Int 2021, 47: 8375-81.

[34] Baskut S, Sert A, Celik ON, Turan S. Anisotropic mechanical and tribological properties of SiAlON matrix composites containing different types of GNPs. J Eur Ceram Soc 2021, 41: 187890.

[35] Suda Y, Kamigaki Y, Miyagawa H, Takeda T, Takahashi K, Hirosaki N. Effects of $\mathrm{Eu}^{2+}$ on the luminescence and afterglow that arise from defects in beta-SiAlON: $\mathrm{Eu}^{2+}$. J Phys D-Appl Phys 2021, 54: 11 .

[36Li YS, Zou B, Shi ZY, Huang CZ, Li L, Liu HL, Zhu HT, Yao P, Liu JK. Wear patterns and mechanisms of sialon ceramic end-milling tool during high speed machining of nickel-based superalloy. Ceram Int 2021, 47: 5690-8.

[37] Yin CF, Li XC, Chen PG, Zhu YL, Zhu BQ. Morphological regulation and simulation of betaSialon and its effect on thermo-mechanical properties of $\mathrm{Al}_{2} \mathrm{O}_{3}-\mathrm{C}$ refractories. Ceram Int 2020, 46: 14597-604. 
[38]Zhang M, Chen Z, Huang JT, Wang SQ, Xiong QM, Feng ZJ, Liu QW, Sun ZH, Li XB. In situ nitriding reaction formation of beta-Sialon with fibers using transition metal catalysts. Ceram Int 2019, 45: 21923-30.

[39] Li Q, Yang ZH, Zhong J, Sun YS, Jia DC, Duan XM, Zhou Y. Effect of the starting AlN content on the phase formation and property of the novel in-situ fabricated X-SiAlON/BN composites. $J$ Eur Ceram Soc 2019, 39: 934-43.

[40] Yan O, Liu Q, Liu QF, Synthesis of rod-like high-purity b-Sialon powder by a novel carbothermal reduction-nitridation method with a nanocasting procedure, J Am Ceram Soc 2010, 93:2470-72.

[41] Liang, Xie, Dongxu, Yao, Yongfeng, Xia, Jinwei, Yin, Hanqin, Liang. High porosity Ca- $\alpha-\mathrm{SiAlON}$ ceramics with rod-like grains fabricated by freeze casting and pressureless sintering. J Eur Ceram Soc 2019, 39: 2036-41.

[42]Zhang J, Bu JL, Wang RL, Wang ZF. Fabrication of Pressureless Sintered $\beta-S i a l o n-\mathrm{ZrO}_{2}$ Composites. Adv Mater Res 2011, 284-286: 335-8.

[43] Hyuga H, Kondo N, Kita H. Fabrication of Dense $\beta$-SiAlON Ceramics with ZrO2 Additions Via a Rapid Reaction-Bonding and Postsintering Route. J Am Ceram Soc 2011, 94: 1014-8.

[44] Wu SS, Xia L, Shi B, Wen G. Microscopic scale evidence of phase transformation process in barium aluminosilicate glass-ceramic. J Eur Ceram Soc 2018, 38: 727-33.

[45] Ye F, Liu LM, Zhang JX, Iwasa M, Su CL. Synthesis of silicon nitride-barium aluminosilicate selfreinforced ceramic composite by a two-step pressureless sintering. Compos Sci Technol 2005, 65: 2233-9.

[46] Ye F, Zhou Y, Lei TC, Yang JM, Zhang LT. Microstructure and mechanical properties of barium aluminosilicate glass-ceramic matrix composites reinforced with SiC es. J Mater Sci 2001, 36: 2575-80.

[47] Allemand A, Guerin C, Besnard C, Billard R, Le Petitcorps Y. A comparison between a new Ultra Fast Pressureless Sintering (UFPS) technology and Spark Plasma Sintering (SPS) for Barium AluminoSilicate metastable phase. J Eur Ceram Soc 2021, 41: 1524-9.

[48] Sun SJ, Xia L, Zhang T, Yang H, Qin CL, Zhong B, Xiong L, Wu X, Wen GW. Synthesis and microstructure evolution of beta-Sialon fibers/barium aluminosilicate (BAS) glass-ceramic matrix composite with enhanced mechanical properties. J Am Ceram Soc 2021. In press

[49] Tong Z, Ji H, Li X, Liu Z. Microstructure control and optimization of low temperature pressureless sintered silicon nitride-barium aluminosilicate composites. J Eur Ceram Soc 2020, 40: 4177-83.

[50] Han Z, Fina A. Thermal conductivity of carbon nanotubes and their polymer nanocomposites: A review. Prog Polym Sci 2011, 36: 914-44.

[51]He G, Li X, Dai Y, Yang Z, Zeng C, Lin C, He S. Constructing bioinspired hierarchical structure in polymer based energetic composites with superior thermal conductivity. Compos Pt B-Eng 2019, 162: 678-84. 
[52] Suh D, Moon CM, Kim D, Baik S. Ultrahigh Thermal Conductivity of Interface Materials by Silver-Functionalized Carbon Nanotube Phonon Conduits. Adv Mater 2016, 28: 7220-7.

[53] Hashin Z, Shtrikman A. A variational approach to the theory of the effective magnetic permeability of multiphase material. J Appl Phys 1962, 33:3125-31.

[54] Y. Agari, A. Ueda, S. Nagai, Electrical and thermal conductivities of polyethylene composites fifilled with biaxial oriented short-cut carbon fibers. J Appl Polym Sci 1994, 52: 1223-31.

[55] Shenogin S, Xue LP, Ozisik R, Keblinski P, Cahill DG. Role of thermal boundary resistance on the heat flow in carbon-nanotube composites. J Appl Phys 2004, 95: 8136-44.

\section{FIGURE CAPTION}

Fig. 1 Schematic diagram for the preparation of Sialon fibers/BAS composites.

Fig. 2 DSC-TG scans of the C3.5 samples.

Fig. 3 SEM images of samples with different carbon contents: (a)(b) 2.5 wt.\%; (c)(d) 3.0 wt.\%; (e)(f) 3.5 wt. $\%$; (g)(h) 4.0 wt. \%.

Fig. 4 XRD patterns of the samples with different carbon contents.

Fig. 5 TEM images of the $\beta$-Sialon fiber: (a)(b)(d) Typical TEM images of the rod-like structure of $\beta$-Sialon; (c) high resolution image of $\beta$-Sialon; (e)The elemental distribution of C-3.5 sample in (d) area.

Fig. 6 The whole curve of theoretically values predicted by parallel conduction model and series conduction model.

Fig.7 (a) The whole curve of theoretically values predicted by Hashin-Shtrikman conduction model compared with the experimental data; (b) The parameters $X_{\text {interconnectivity }}$ based on Sialon content; (c) The parameters $\eta$ based on Sialon content; (d) The whole curve of theoretically values predicted by 
Agari conduction model; (e) The surface thermal resistance model compared with the experimental data; (f) The contact thermal resistance model compared with the experimental data.

Fig. 8 Schematic illustration of thermal conduction mechanism of composite with different Sialon contents: (a) Low Sialon content; (b) High Sialon content.

Fig. 9 The temperature distribution of samples with different Sialon contents based on finite element method: (a) $\mathrm{C} 2.5$; (b) $\mathrm{C} 3$; (c) $\mathrm{C} 3.5$; (d) $\mathrm{C} 4$. 


\section{Figures}

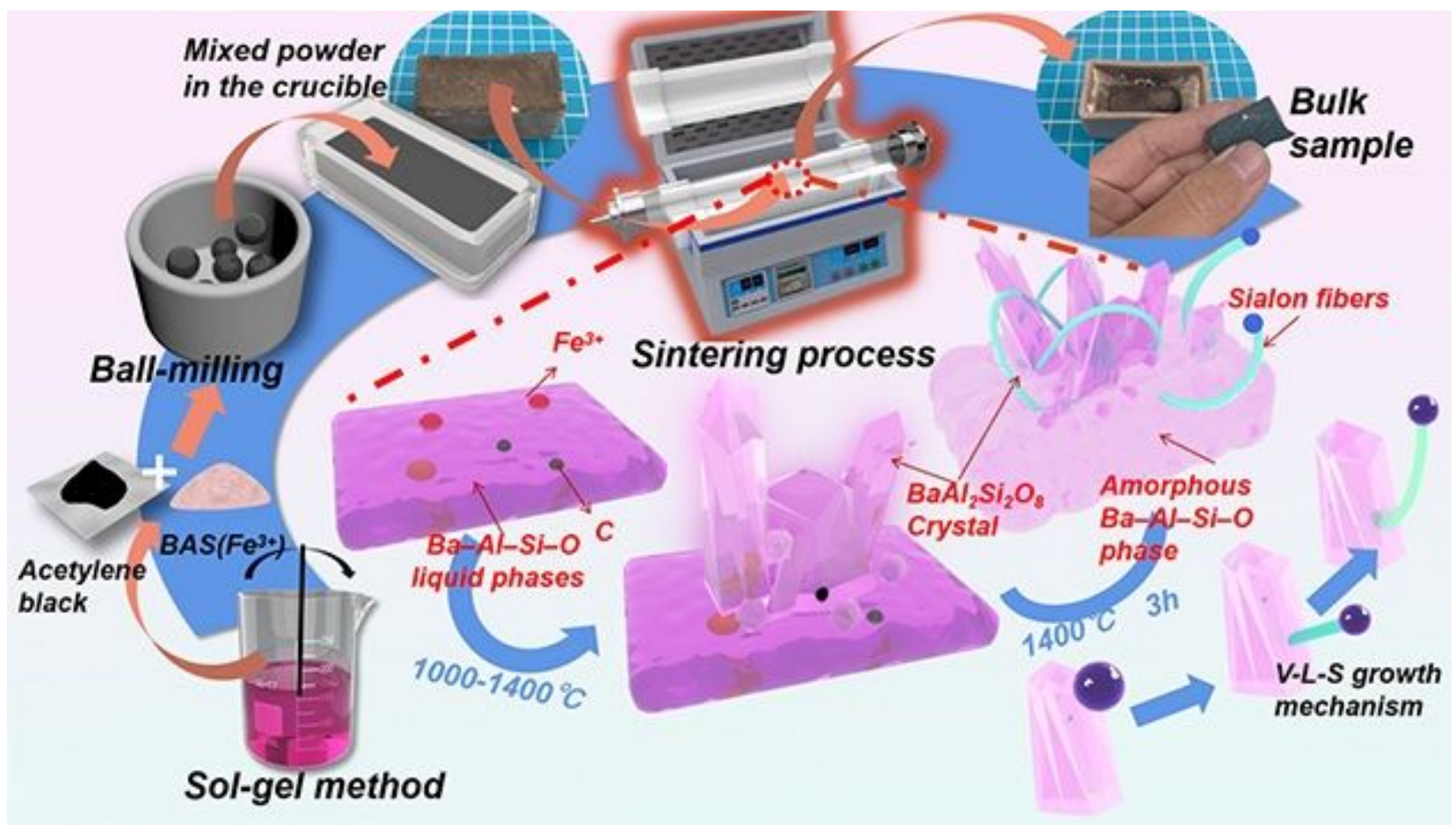

Figure 1

Schematic diagram for the preparation of Sialon fibers/BAS composites. 


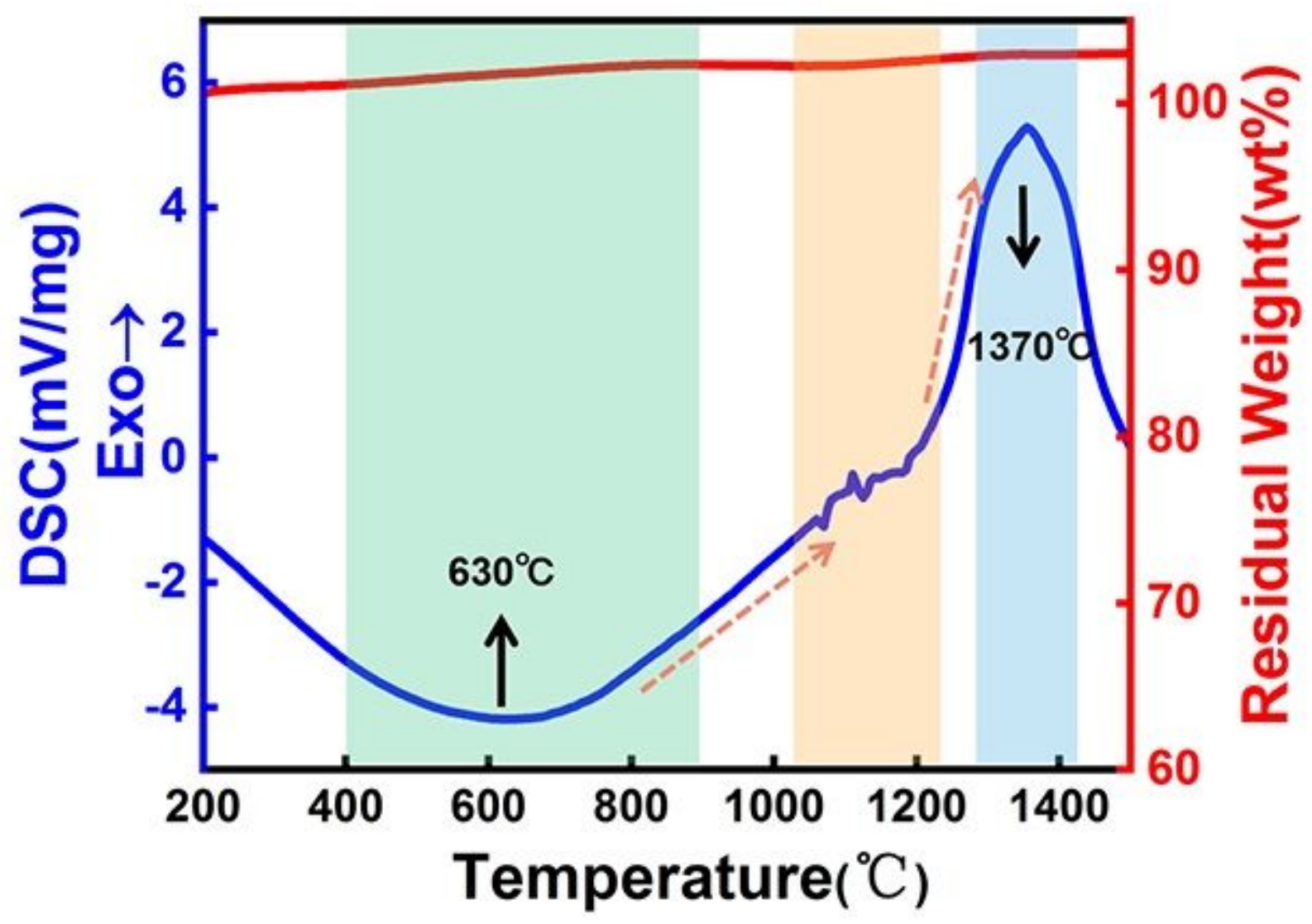

Figure 2

DSC-TG scans of the C3.5 samples.
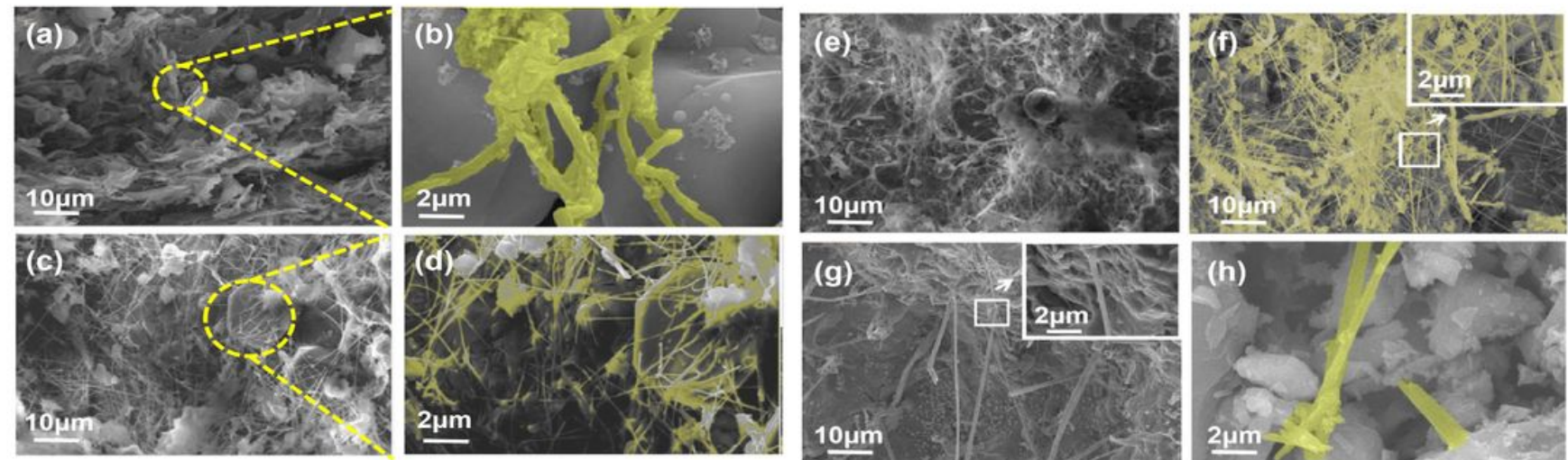

Figure 3

SEM images of samples with different carbon contents: (a)(b) 2.5 wt.\%; (c)(d) 3.0 wt.\%; (e)(f) 3.5 wt.\%; (g) (h) $4.0 \mathrm{wt} . \%$. 


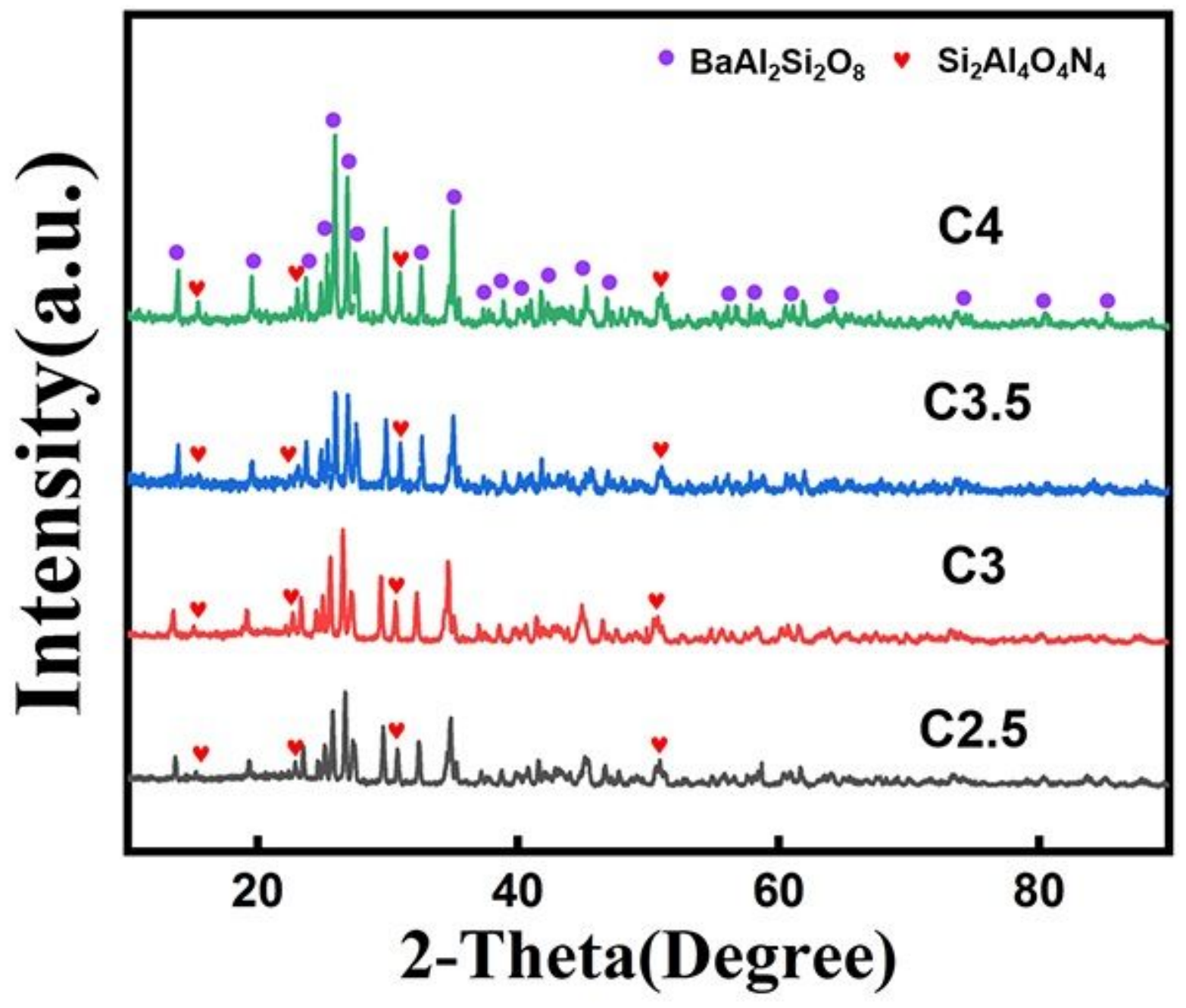

Figure 4

XRD patterns of the samples with different carbon contents.

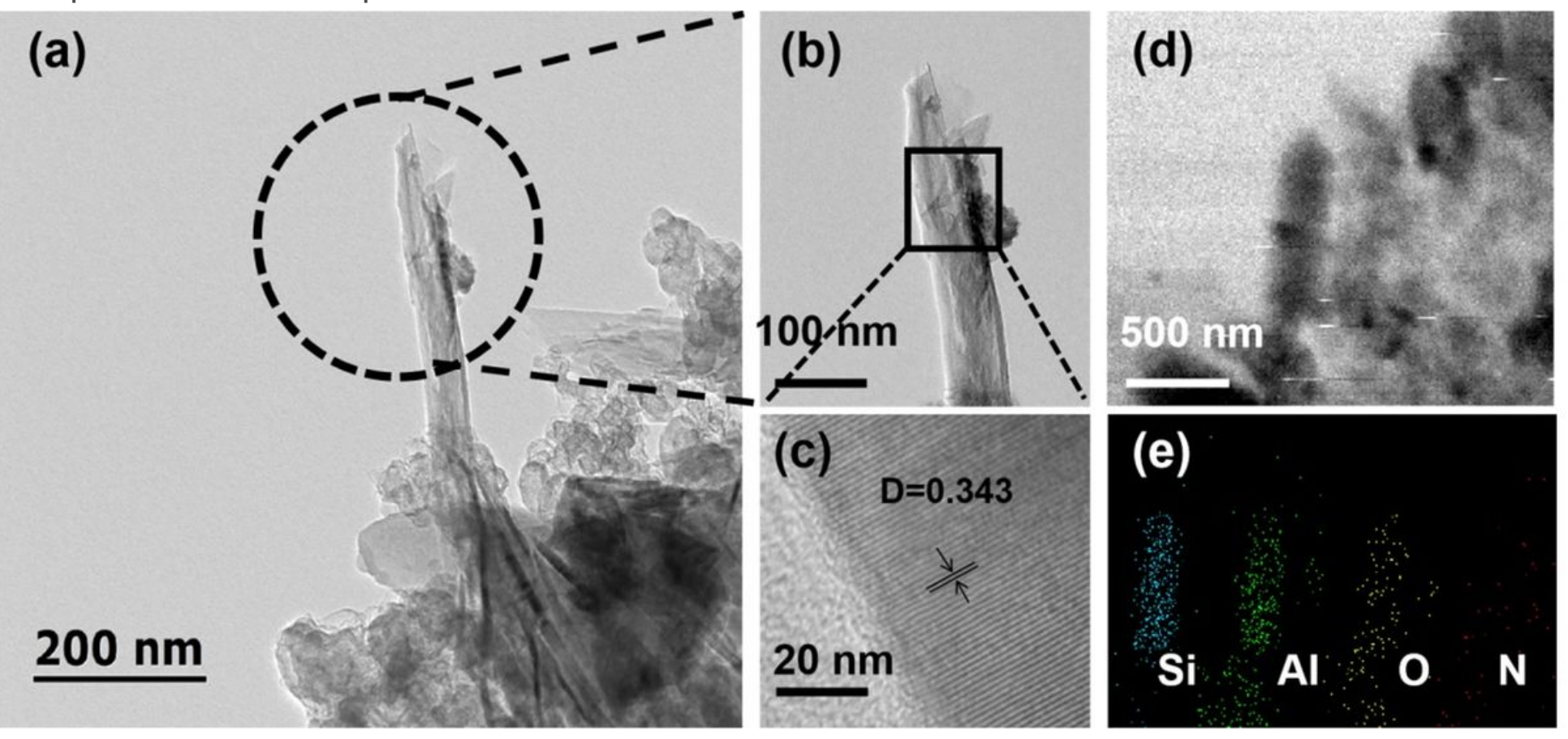


Figure 5

TEM images of the $\beta$-Sialon fiber: (a)(b)(d) Typical TEM images of the rod-like structure of $\beta$-Sialon; (c) high resolution image of $\beta$-Sialon; (e)The elemental distribution of C-3.5 sample in (d) area.

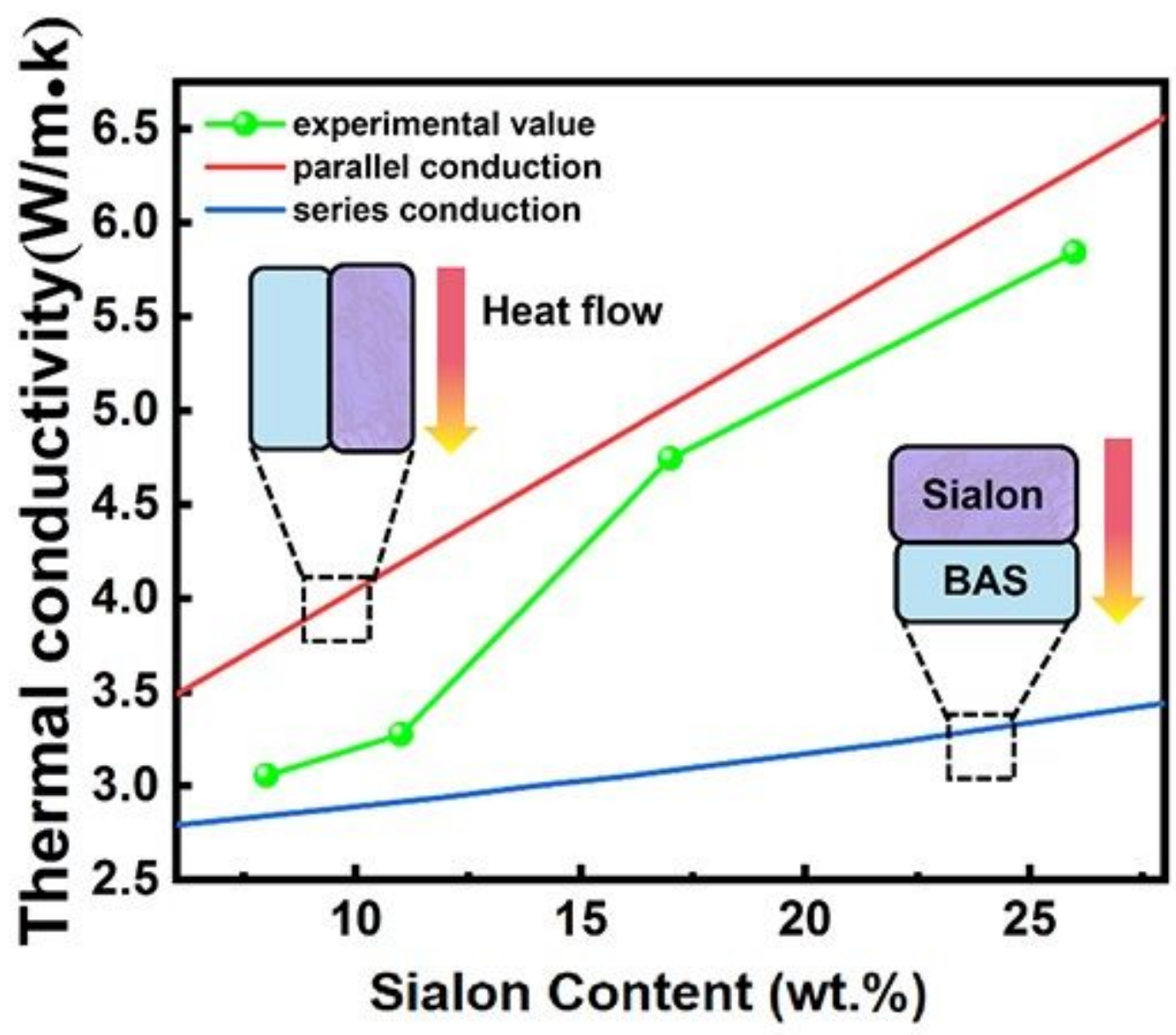

Figure 6

The whole curve of theoretically values predicted by parallel conduction model and series conduction model. 
(a)

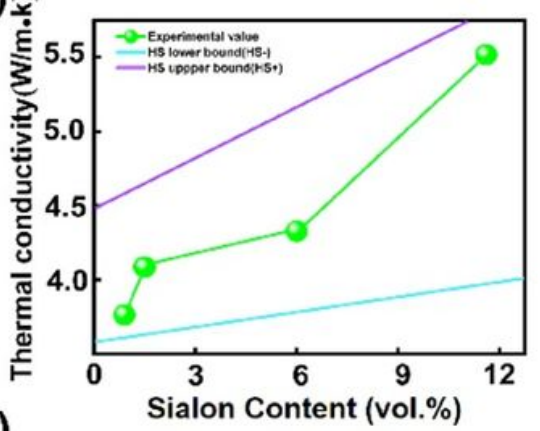

(d)

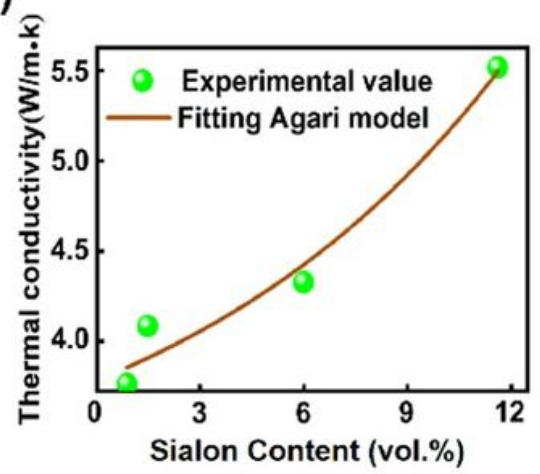

(b)

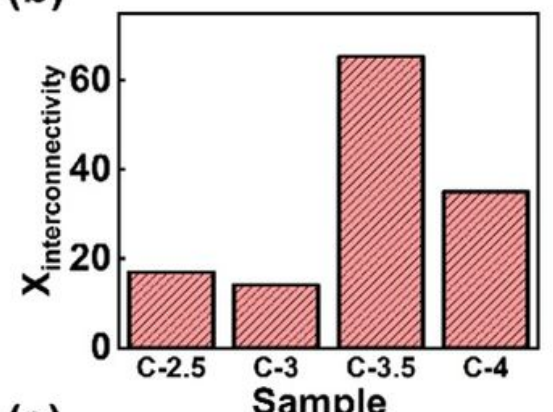

(e)

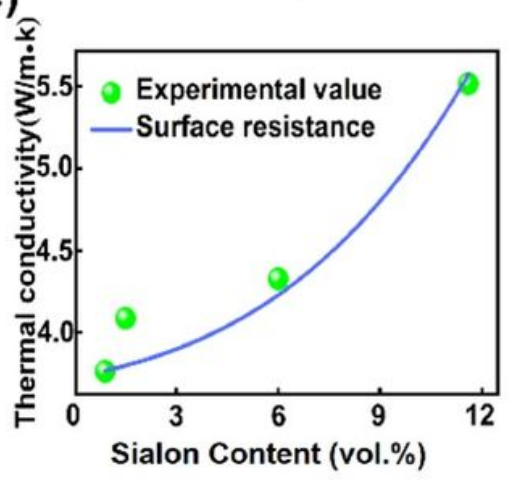

(c)

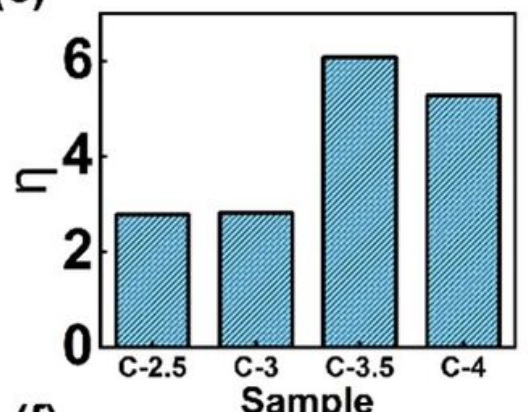

(f)

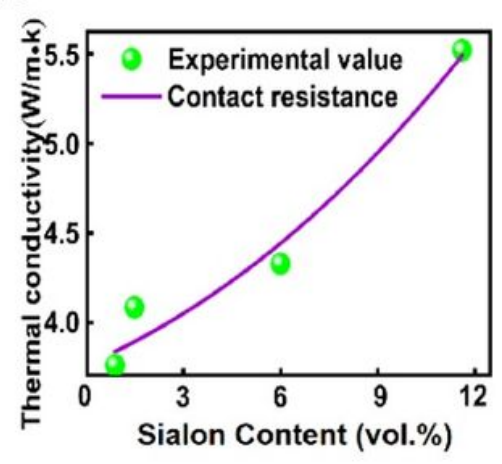

Figure 7

(a) The whole curve of theoretically values predicted by Hashin-Shtrikman conduction model compared with the experimental data; (b) The parameters Xinterconnectivity based on Sialon content; (c) The parameters Xinterconnectivity based on Sialon content; (d) The whole curve of theoretically values predicted by Agari conduction model; (e) The surface thermal resistance model compared with the experimental data; (f) The contact thermal resistance model compared with the experimental data. 

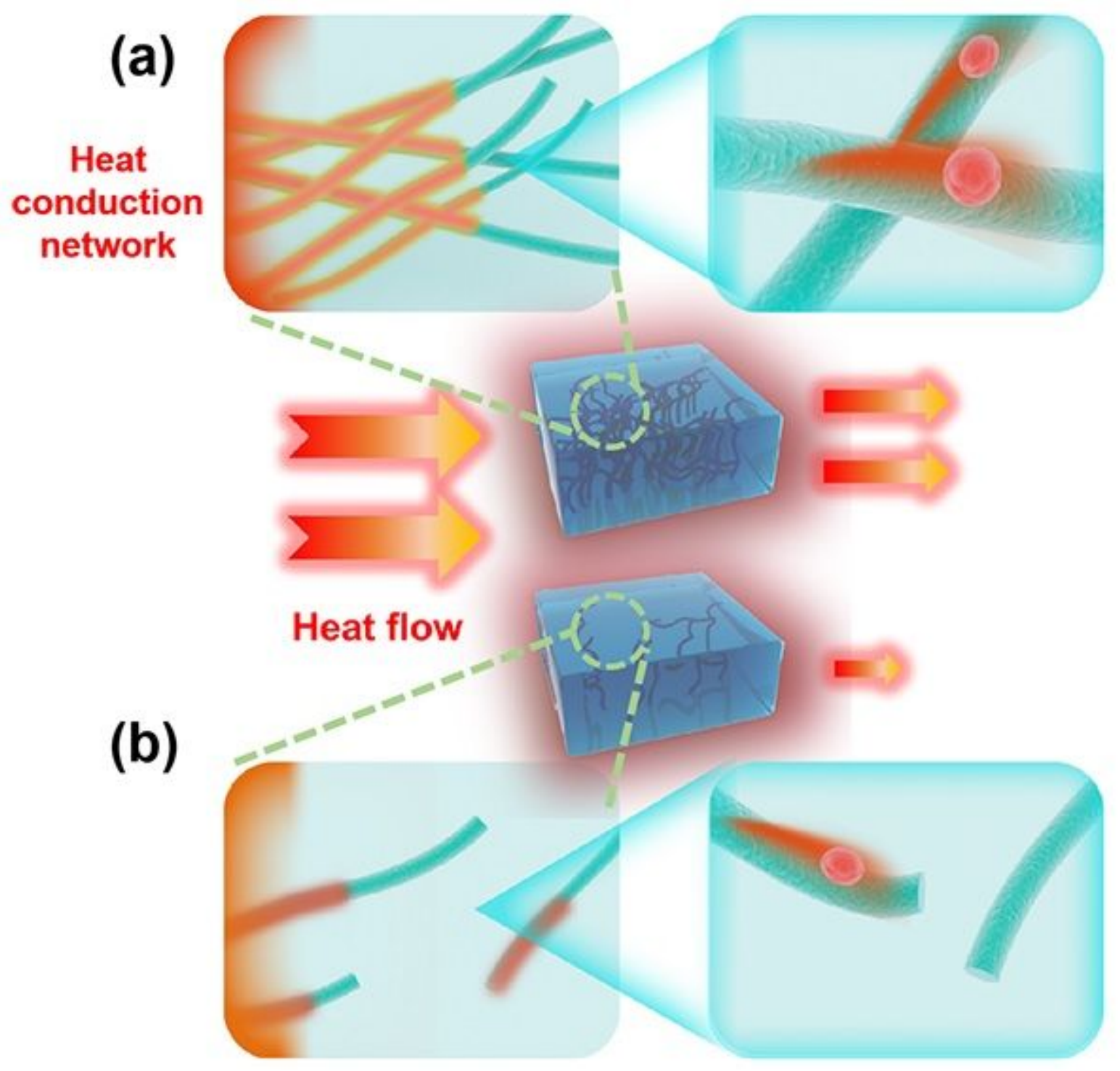

Figure 8

Schematic illustration of thermal conduction mechanism of composite with different Sialon contents: (a) Low Sialon content; (b) High Sialon content. 

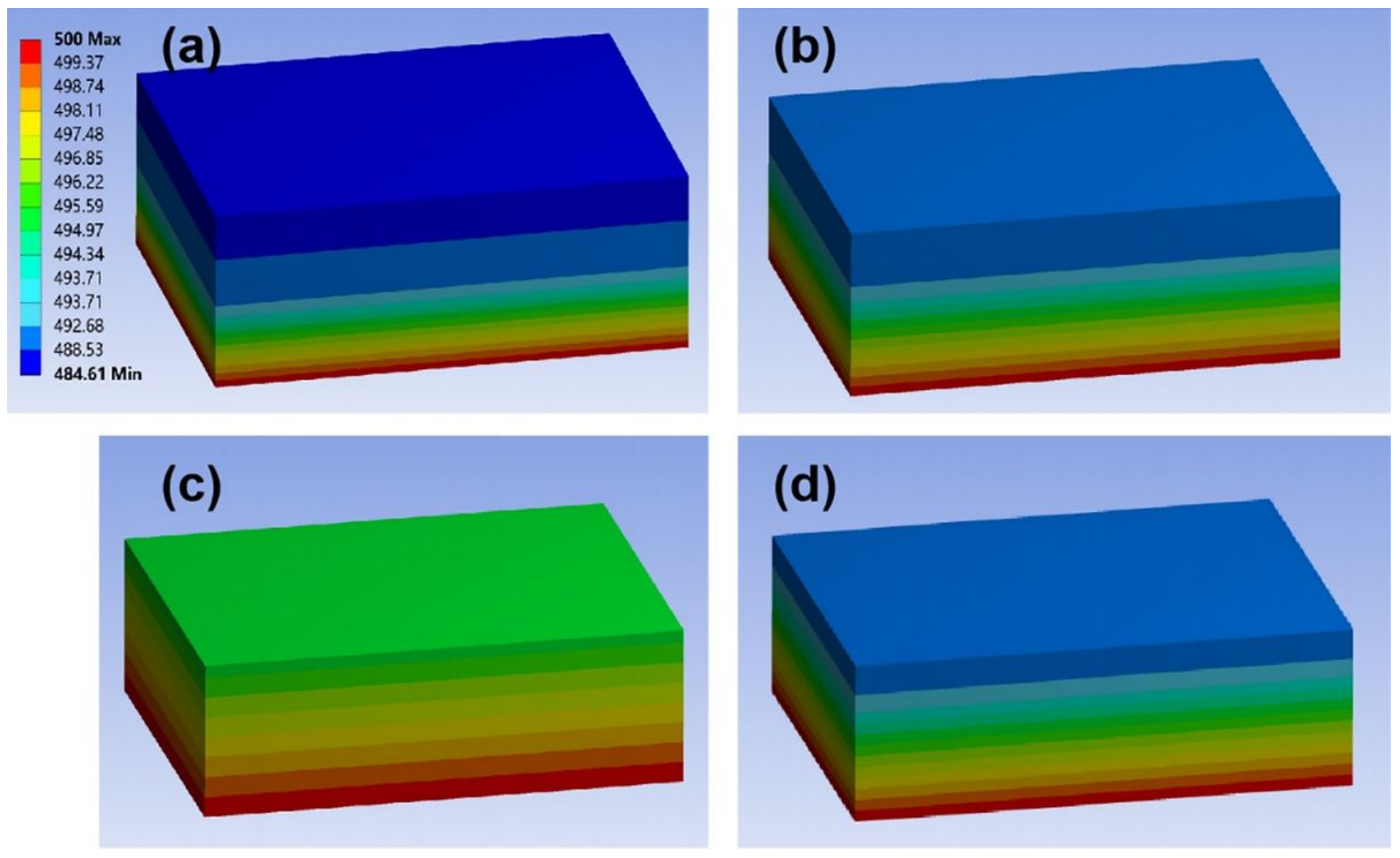

\section{Figure 9}

The temperature distribution of samples with different Sialon contents based on finite element method: (a) C2.5; (b) C3; (c) C3.5; (d) C4.

\section{Supplementary Files}

This is a list of supplementary files associated with this preprint. Click to download.

- SupportingInformation.docx 